\title{
Biosynthesis of Poly(3HB-co-3HP) with Variable Monomer Composition in Recombinant Cupriavidus necator H16
}

\author{
Callum McGregor, Nigel P. Minton, and Katalin Kovács*
}

Cite This: https://doi.org/10.1021/acssynbio.1c00283

Read Online

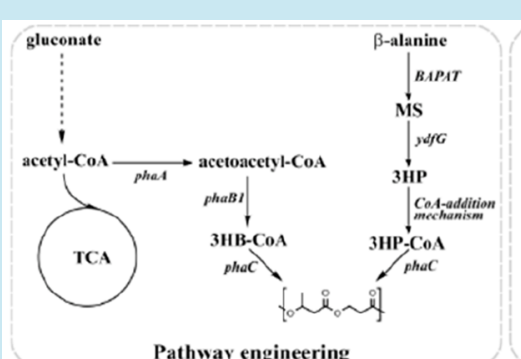

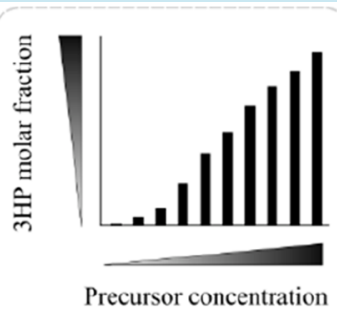

Control of $3 \mathrm{HP}$ mol\%

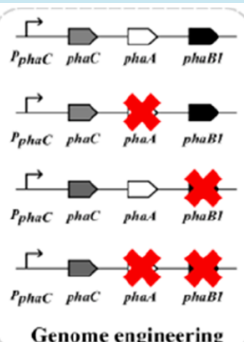

Genome engineering

ABSTRACT: Polyhydroxyalkanoates are attractive alternatives to traditional plastics. However, although polyhydroxybutyrate (PHB) is produced in large quantities by Cupriavidus necator H16, its properties are far from ideal for the manufacture of plastic products. These properties may be improved through its coproduction with 3-hydroxypropionate (3HP), which leads to the formation of the copolymer poly(3-hydroxybutyrate-co-3-hydroxypropionate) (poly(3HB-co-3HP). To achieve this, a pathway was designed to enable $C$. necator $\mathrm{H} 16$ to convert $\beta$-alanine to $3 \mathrm{HP}$. The initial low levels of incorporation of $3 \mathrm{HP}$ into the copolymer were overcome by the overproduction of the native propionyl-CoA transferase together with PHA synthase from Chromobacterium sp. USM2. Following optimization of $3 \mathrm{HP}$ incorporation into the copolymer, the molar fraction of $3 \mathrm{HP}$ could be controlled by cultivation in medium containing different concentrations of $\beta$-alanine. Between 0 and 80 mol \% 3HP could be achieved. Further supplementation with $2 \mathrm{mM}$ cysteine increased the maximum $3 \mathrm{HP}$ molar fraction to $89 \%$. Additionally, the effect of deletions of the phaA and phaB1 genes of the phaCAB operon on $3 \mathrm{HP}$ molar fraction were investigated. A phaAB1 double knockout resulted in a copolymer containing $91 \mathrm{~mol} \% 3 \mathrm{HP}$ without the need for cysteine supplementation.

KEYWORDS: polyhydroxyalkanoates, poly(3-hydroxybutyrate-co-3-hydroxypropionate), Cupriavidus necator H16, PHA synthase, synthetic pathway

A pproximately 380 million tons of plastic was manufactured in 2015, resulting in the generation of around 140 million tons of plastic waste. ${ }^{1}$ Traditional plastics are recalcitrant in nature, leading to accumulation in the environment and damage to natural ecosystems. Furthermore, the supply of fossil fuels from which plastics are produced is finite. As such, alternative materials available from renewable feedstocks are needed. Polyhydroxyalkanoates (PHAs) are a class of polymers accumulated intracellularly by various bacteria when encountering conditions of nutrient limitation and carbon excess. ${ }^{2}$ PHAs represent attractive alternatives to traditional plastics as the thermal and mechanical properties are similar. Additionally, PHAs are biodegradable and can be produced by the microbial fermentation of renewable carbon sources such as sugars, oils, and gases, rather than fossil fuels. $^{3-8}$ As a result, PHAs have attracted significant research and industry interest.

The most widely studied PHA is poly(3-hydroxybutyrate) (PHB). The enzyme components of the biosynthetic pathway responsible for $\mathrm{PHB}$ production in the model organism Cupriavidus necator H16 (C. necator H16) are encoded by the phaCAB operon. ${ }^{9}$ First, two molecules of acetyl-CoA are condensed to form acetoacetyl-CoA in a reaction catalyzed by a $\beta$-ketothiolase (PhaA). The acetoacetyl-CoA is then reduced to 3-hydroxybutyryl-CoA (3HB-CoA) by an NADPH-dependent acetoacetyl-CoA reductase ( $\mathrm{PhaB} 1)$. Lastly, polymerization of $3 \mathrm{HB}-\mathrm{CoA}$ into $\mathrm{PHB}$ is facilitated by the PHA synthase (PhaC). Understanding of the PHB biosynthetic pathway and advances in metabolic engineering have also allowed production of PHB in non-natural producers such as Escherichia coli. ${ }^{10}$ The properties of $\mathrm{PHB}$, while similar to plastic, are not ideal. ${ }^{11}$ Thermal degradation occurs at temperatures close to the melting point, and high crystallinity results in a brittle material. ${ }^{12,13}$ Consequently, the widespread

Received: June 21, 2021 
application of PHB-based products has yet to be realized. The properties of PHAs can be altered by changing the monomeric composition of the polymer. More than 160 hydroxyalkanoate (HA) monomers have been identified to date. ${ }^{14}$ Furthermore, PHA synthases exhibit relatively broad substrate specificity, allowing incorporation of different $\mathrm{HA}$ monomers into the polymer, resulting in a copolymer. ${ }^{15}$ As a consequence, the potential for producing PHAs with improved properties is vast. Copolymers consisting of 3-hydroxybutyrate $(3 \mathrm{HB})$ and a second monomer, such as 3-hydroxypropionate (3HP), 3hydroxyvalerate $(3 \mathrm{HV})$, or 3 -hydroxyhexanoate $(3 \mathrm{HHx})$ have been previously produced. ${ }^{16-18}$ In particular, poly(3HB-co$3 \mathrm{HP})$ copolymers showed decreased crystallinity, melting temperature, and glass transition temperature, when compared to PHB. ${ }^{13,19-24}$

The biosynthesis of poly(3HB-co-3HP) was first described in $1991 .^{19}$ Following cultivation of C. necator $\mathrm{H} 16$ with $3 \mathrm{HP}$, 1,5-pentanediol, or 1,7-heptanediol, it was possible to accumulate poly(3HB-co-3HP). The $3 \mathrm{HP}$ molar fraction, however, was limited to $7 \mathrm{~mol} \% 3 \mathrm{HP}$ and under. Subsequently it was shown that $C$. necator $\mathrm{H} 16$ could be engineered to produce poly (3HB-co-3HP) from fructose by expression of genes encoding malonyl-CoA reductase and a $3 \mathrm{HP}-\mathrm{CoA}$ synthetase domain of propionyl-CoA synthetase from Chloroflexus aurantiacus. ${ }^{16}$ In this case poly(3HB-co-3HP) was produced using fructose as the sole carbon source; however, the highest $3 \mathrm{HP}$ molar fraction achieved by $\mathrm{C}$. necator $\mathrm{H} 16$ was $1 \mathrm{~mol} \% 3 \mathrm{HP}$. While even low 3HP molar fraction influences the properties of poly (3HB-co-3HP) compared to $\mathrm{PHB}$, more desirable properties can be obtained with higher $3 \mathrm{HP}$ content. $^{25}$ These studies indicate that while C. necator H16 is capable of incorporating $3 \mathrm{HP}$ into the growing copolymer chain, the process is inefficient and only low $3 \mathrm{HP}$ content is attained.

Various routes to $3 \mathrm{HP}$-containing copolymers have been described. ${ }^{16,26-30}$ One of the most common is the glycerolutilizing pduP pathway, first described by Andreessen et al. ${ }^{31}$ The pduP route describes a pathway by which glycerol is first converted to 3-hydroxypropionaldehyde by glycerol dehydratase, using vitamin $\mathrm{B} 12$ as a cofactor. The 3-hydroxypropionaldehyde is subsequently converted to $3 \mathrm{HP}-\mathrm{CoA}$ by propionaldehyde dehydrogenase. Lastly, $3 \mathrm{HP}-\mathrm{CoA}$ is polymerized by the activity of a PHA synthase. The pathway takes its name from the propionaldehyde dehydrogenase, which is encoded by the $p d u P$ gene, ${ }^{32}$ and has been widely used for the production of poly $(3 \mathrm{HP})$ and $\operatorname{poly}(3 \mathrm{HB}-\mathrm{co}-3 \mathrm{HP}) .^{27,31,33-35}$ The pduP pathway is reliant on glycerol dehydratase, which requires vitamin $\mathrm{B} 12$ as a cofactor. As most bacteria do not naturally produce vitamin $\mathrm{B} 12$, this expensive cofactor must be added to the medium. While this has been avoided by using organisms which synthesize vitamin $\mathrm{B} 12,{ }^{36,37}$ the biosynthetic pathway for this cofactor is absent in C. necator $\mathrm{H}_{16}{ }^{38}$

Another option is the malonyl-CoA route, which has been used to produce poly (3HB-co-3HP) in C. necator $\mathrm{H} 16$, and poly (3HP) in E. coli. ${ }^{16,39}$ In this case, acetyl-CoA is converted to malonyl-CoA by acetyl-CoA carboxylase, then malonyl-CoA is reduced to $3 \mathrm{HP}$ by malonyl-CoA reductase. The $3 \mathrm{HP}$ must then be activated to $3 \mathrm{HP}-\mathrm{CoA}$, which can be facilitated by overexpression of a $\mathrm{CoA}$ ligase or $\mathrm{CoA}$ transferase. As before, incorporation of $3 \mathrm{HP}-\mathrm{CoA}$ into the copolymer is then catalyzed by the action of a PHA synthase. Unlike the pduP pathway, which is restricted to glycerol as the carbon source, the malonyl-CoA pathway presents the advantage of being able to use any carbon source. However, the activity of malonylCoA reductase is reduced, since the optimum growth temperature of $\mathrm{C}$. necator $\mathrm{H} 16$ is $30{ }^{\circ} \mathrm{C}$, while malonyl-CoA reductase exhibits highest activity at around $55-57^{\circ} \mathrm{C} .{ }^{16,39}$

A more recently described pathway for the production of $3 \mathrm{HP}$ is via $\beta$-alanine. ${ }^{40,41}$ In this route, $\beta$-alanine derived from the tricarboxylic (TCA) cycle is converted to malonic semialdehyde and then to 3HP. The $\beta$-alanine pathway has previously been used for the production of poly $(3 \mathrm{HP})$ in E. coli. ${ }^{28,42}$ Since the $3 \mathrm{HP}$ is derived from the TCA cycle, a wide range of carbon sources can be used. While a full $\beta$ alanine route which provides $3 \mathrm{HP}$ from the TCA has not yet been established in $\mathrm{C}$. necator $\mathrm{H} 16$, it was chosen to investigate the ability of $C$. necator $\mathrm{H} 16$ to produce poly $(3 \mathrm{HB}-c o-3 \mathrm{HP})$ when grown in medium supplemented with $\beta$-alanine (Figure $1)$.

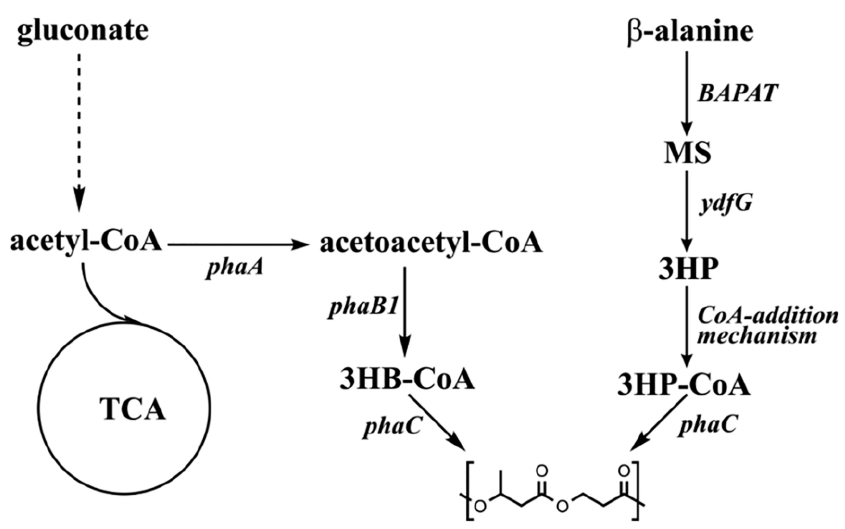

Figure 1. Schematic for the biosynthesis of poly (3HB-co-3HP) by engineered $C$. necator $\mathrm{H} 16$. The $3 \mathrm{HP}$ monomer is produced by conversion of exogenously supplemented $\beta$-alanine via malonic semialdehyde (MS). Activation of $3 \mathrm{HP}$ to $3 \mathrm{HP}-\mathrm{CoA}$ is facilitated by a CoA-addition mechanism. Gluconate is metabolized to acetylCoA which is converted to PHB by the action of the enzymes encoded by the phaCAB operon. Incorporation of $3 \mathrm{HP}$ monomer units into the growing polymer chain results in the biosynthesis of poly (3HB-co-3HP).

In this work, the biosynthesis of poly(3HB-co-3HP) using engineered $C$. necator $\mathrm{H} 16$ cultivated in medium containing $\beta$ alanine is reported. Strains containing the engineered pathway were able to produce poly $(3 \mathrm{HB}-\mathrm{co}-3 \mathrm{HP})$ with a range of $3 \mathrm{HP}$ molar content between 0 and $80 \mathrm{~mol} \% 3 \mathrm{HP}$ depending on the amount of $\beta$-alanine supplied. Additional supplementation with cysteine was used to increase $3 \mathrm{HP}$ molar fraction to 89 mol \%. Deletion of genes of the phaCAB operon was shown to have a positive effect on $3 \mathrm{HP}$ molar fraction; simultaneous deletion of both phaA and phaB1 resulted in up to $91 \mathrm{~mol} \%$ $3 \mathrm{HP}$ in the copolymer without the need for cysteine supplementation.

\section{RESULTS AND DISCUSSION}

Operon Structures of Plasmids Tested for Improved Synthesis of Poly(3HB-co-3HP). To improve the ability of C. necator $\mathrm{H} 16$ to incorporate $3 \mathrm{HP}$ into the polymer, several plasmids were constructed and tested (Table 1). A systematic approach was employed. First, a pathway was assembled that would enhance the conversion of exogenously supplied $\beta$ alanine to 3HP. Previously it was shown that the expression of genes encoding a $\beta$-alanine pyruvate aminotransferase 
Table 1. Strains and Plasmids ${ }^{a}$

\begin{tabular}{|c|c|c|}
\hline strain or plasmid & description & $\begin{array}{l}\text { source or } \\
\text { reference }\end{array}$ \\
\hline \multicolumn{3}{|l|}{ Escherichia coli } \\
\hline $\mathrm{DH} 5 \alpha$ & Used in plasmid construction & 52 \\
\hline S17-1 & Donor in conjugative plasmid transfer & 53 \\
\hline \multicolumn{3}{|l|}{ Cupriavidus necator } \\
\hline $\mathrm{H} 16$ & Wild type & $\begin{array}{l}\text { DSMZ, } \\
\text { Germany }\end{array}$ \\
\hline$\Delta 3$ & $\begin{array}{l}\text { Derivative of } \mathrm{H} 16 ; \Delta m m s A 1 \Delta m m s A 2 \\
\quad \Delta m m s A 3\end{array}$ & 54 \\
\hline$\Delta 3 \mathrm{~A}$ & Derivative of $\Delta 3 ; \Delta p h a A$ & This study \\
\hline$\Delta 3 \mathrm{~B} 1$ & Derivative of $\Delta 3 ; \Delta p h a B 1$ & This study \\
\hline$\Delta 3 \mathrm{AB} 1$ & Derivative of $\Delta 3 ; \Delta p h a A B 1$ & This study \\
\hline \multicolumn{3}{|l|}{ Plasmids } \\
\hline pMTL71301 & $\begin{array}{l}\text { Broad host range plasmid; pBBR1 origin } \\
\text { of replication, } \mathrm{Tet}^{\mathrm{r}}\end{array}$ & 55 \\
\hline peyfP & pMTL71301 derivative; $P_{p h a C}$ eyf $P$ & This study \\
\hline pCNCMO & $\begin{array}{l}\text { pMTL71301 derivative; } P_{p h a c}, B A P A T_{C v}, \\
y d f G_{E c}\end{array}$ & This study \\
\hline pCNCM12 & $\begin{array}{l}\text { pMTL71301 derivative; } P_{p h a C}, B A P A T_{C v} \\
\quad y d f G_{E \mathcal{U}}, T_{\text {rrnB }}, p r p E_{C n}, P_{t r p}\end{array}$ & This study \\
\hline pCNCM13 & $\begin{array}{l}\text { pMTL71301 derivative; } P_{p h a C}, B A P A T_{C v}, \\
\quad y d f G_{E c}, T_{\text {rrnB }}, p c t_{C n}, P_{t r p}\end{array}$ & This study \\
\hline pCNCM14 & $\begin{array}{l}\text { pMTL71301 derivative; } P_{p h a C}, B A P A T_{C v}, \\
\quad y d f G_{E \mathcal{C}}, T_{\mathrm{rrnB}}, p r p E_{E \mathcal{O}}, P_{t r p}\end{array}$ & This study \\
\hline pCNCM15 & $\begin{array}{l}\text { pMTL71301 derivative; } P_{p h a C}, B A P A T_{C v} \text {, } \\
\quad y d f G_{E \mathcal{C}}, T_{\mathrm{rrnB}}, \text { ato } A D_{E \mathcal{C}}, P_{t r p}\end{array}$ & This study \\
\hline pCNCM17 & $\begin{array}{l}\text { pMTL71301 derivative; } P_{p h a C}, B A P A T_{C v}, \\
\quad y d f G_{E \mathcal{c}}, T_{\mathrm{rrnB}}, p h a C_{C n}, p c t_{C n}, P_{t r p}\end{array}$ & This study \\
\hline pCNCM21 & $\begin{array}{l}\text { pMTL71301 derivative; } P_{p h a C}, B A P A T_{C v} \text {, } \\
\quad y d f G_{E c}, T_{\text {rrnB }}, p h a C_{C s}, p c t_{C n}, P_{t r p}\end{array}$ & This study \\
\hline pMTL70641 & Suicide vector; $s a c B$ and $\mathrm{Tet}^{\mathrm{r}}$ & 55 \\
\hline pCNCM_phaA & $\begin{array}{l}\text { pMTL70641 carrying deletion cassette } \\
\text { for phaA }\end{array}$ & This study \\
\hline pCNCM_phaB1 & $\begin{array}{l}\text { pMTL70641 carrying deletion cassette } \\
\text { for phaB1 }\end{array}$ & This study \\
\hline pCNCM_phaAB1 & $\begin{array}{l}\text { pMTL70641 carrying deletion cassette } \\
\text { for phaAB1 }\end{array}$ & This study \\
\hline
\end{tabular}

(BAPAT) and an NADP-dependent 3-hydroxyacid dehydrogenase (ydfG) was sufficient for the production of $3 \mathrm{HP}$ from $\beta$-alanine in yeast, as well as during the production of poly (3HP) in E. coli. ${ }^{28,40,42}$ Accordingly, a pathway to the $3 \mathrm{HP}$ monomer from $\beta$-alanine was assembled comprising genes coding for a putative BAPAT from Chromobacterium violaceum, and YdfG from E. coli. The respective genes, $B A P A T_{C v}$ and $y d f G_{E c}$, were positioned downstream of the promoter of the phaC gene $\left(\mathrm{P}_{\text {phaC }}\right)$, resulting in plasmid pCNCM0.

Since PHA synthases act strictly on hydroxyacyl-CoA (HACoA) substrates, ${ }^{43}$ it was hypothesized that increased activation of $3 \mathrm{HP}$ to $3 \mathrm{HP}-\mathrm{CoA}$ would improve incorporation of $3 \mathrm{HP}$ into the copolymer. Therefore, the effect of overproducing a "CoA-addition" mechanism on 3HP incorporation was tested. The effectiveness of four different enzymes in converting $3 \mathrm{HP}$ to $3 \mathrm{HP}-\mathrm{CoA}$ in $\mathrm{C}$. necator $\mathrm{H} 16$ were evaluated. These were propionyl-CoA synthetase $\left(\operatorname{PrpE}_{\mathrm{Cn}}\right)$ and propionyl-CoA transferase $\left(\mathrm{Pct}_{\mathrm{Cn}}\right)$ from C. necator $\mathrm{H} 16$, as well as propionyl-CoA synthetase $\left(\operatorname{PrpE}_{\mathrm{Ec}}\right)$ and acetoacetyl-CoA acetyltransferase $\left(A_{\text {to }} \mathrm{AD}_{\mathrm{Ec}}\right)$ from $E$. coli. $\mathrm{Pct}_{\mathrm{Cn}}$ has been previously shown to catalyze the transfer of CoA from acetyl$\mathrm{CoA}$ to $3 \mathrm{HP}^{44,45}$ and exploited for the production of copolymers containing medium-chain-length hydroxyalkanoate monomers. ${ }^{46}$ While $\operatorname{PrpE}_{\mathrm{Ec}}$ has been used previously for production of $3 \mathrm{HP}$-containing polymers, ${ }^{37,39,42}$ both $\operatorname{PrpE}_{\mathrm{Cn}}$ and Ato $\mathrm{AD}_{\mathrm{Ec}}$ have been used in the production of $3 \mathrm{HV}$ containing polymers as a mechanism for activating propionate to propionyl-CoA. ${ }^{47,48}$ Each of the respective CoA-addition mechanisms were individually cloned downstream of the promoter of the trp gene $\left(\mathrm{P}_{t r p}\right)$, resulting in plasmids pCNCM12-15. The $\mathrm{P}_{t r p}$ promoter has been utilized in C. necator $\mathrm{H} 16$ for the production of PHAs, where it was shown to be stronger than the $\mathrm{P}_{\text {phac }}$ promoter ${ }^{49}$

Lastly, to increase incorporation of $3 \mathrm{HP}$ into the copolymer, two different PHA synthases were evaluated. As the $C$. necator H16 PHA synthase has previously been shown to have a much lower substrate specificity for $3 \mathrm{HP}$ than $3 \mathrm{HB},{ }^{50,51}$ its overproduction is likely to result in higher levels of $3 \mathrm{HP}$ incorporation into the copolymer. Overexpression of its encoding gene was, therefore, tested. For comparative purposes, the overproduction of a PHA synthase from Chromobacterium sp. USM2 (C. sp. USM2) was also explored. During this work it was found that $\mathrm{Pct}_{\mathrm{Cn}}$ was the most effective CoA-addition mechanism. Accordingly, the genes encoding the two PHA synthases were positioned individually downstream of $p c t_{C n}$, resulting in plasmids CNCM17 and $\Delta 3$ CNCM21, respectively. The PHA synthase of $C$. necator $\mathrm{H} 16$ has previously been used extensively for the production of various 3HP-containing polymers. ${ }^{26,27,29,33}$ On the other hand, the PHA synthase from Chromobacterium sp. USM2 was used in the production of poly $(3 \mathrm{HP}){ }^{35}$ The components and arrangement structure of the synthetic operons in the constructed plasmids is shown in Figure 2.

Construction of a 3HP-Producing Strain of $C$. necator H16. The first aim was to produce $3 \mathrm{HP}$ from exogenously supplied $\beta$-alanine. Therefore, plasmid pCNCM0 was constructed, which encodes $B A P A T_{C v}$ and $y d f G_{E c}$. To avoid consumption of any $3 \mathrm{HP}$ synthesized, a previously described mutant strain of $C$. necator $\mathrm{H} 16$ was chosen as the host for this study. ${ }^{54}$ This strain, C. necator $\mathrm{H} 16 \Delta 3$, is unable to use $3 \mathrm{HP}$ as a carbon source. Transformation of $\Delta 3$ with plasmid pCNCM0 resulted in strain $\Delta 3$ _CNCM0 which should be able to produce $3 \mathrm{HP}$ when grown in medium supplemented with $\beta$-alanine, facilitated by the expression of $B A P A T_{C v}$ and $y d f G_{E c}$. As a control, a plasmid expressing eyf $P$ under the control of the $\mathrm{P}_{\text {phac }}$ promoter was constructed and transformed into $\Delta 3$, resulting in the control strain $\Delta 3$ _efyP. Strains $\Delta 3$ CNCM0 and $\Delta 3$ _efyP were cultivated in SGMM supplemented with $50 \mathrm{mM} \beta$-alanine. HPLC analysis revealed secretion of approximately $40 \mathrm{mM} 3 \mathrm{HP}$ into the supernatant by strain $\Delta 3$ CNCM0, while no $3 \mathrm{HP}$ was observed in strain $\Delta 3$ _eyfP (Figure 3 ). Since $3 \mathrm{HP}$ was detected in the supernatant of strain $\Delta 3$ CNCM0, this suggested that it was not being incorporated the PHB polymer. Indeed, only 1.27 mol \% 3HP was detected in the copolymer produced by strain $\Delta 3$ CNCM0. As expected, the polymer produced by strain $\Delta 3$ _eyfP was a PHB homopolymer (Table 2).

PHA synthases act strictly on HA-CoA substrates. ${ }^{43}$ Therefore, 3HP must be activated to 3HP-CoA before incorporation into the polymer by a PHA synthase. The results presented in Table 2 showed the molar fraction of $3 \mathrm{HP}$ was low, suggesting insufficient conversion of $3 \mathrm{HP}$ to $3 \mathrm{HP}-$ CoA. Previous studies have also reported low $3 \mathrm{HP}$ molar fractions as a result of inadequate generation of $3 \mathrm{HP}-\mathrm{CoA} .{ }^{16,36}$ This has been overcome by increasing the capacity of the cell to add a CoA moiety to $3 \mathrm{HP} .^{56}$ 

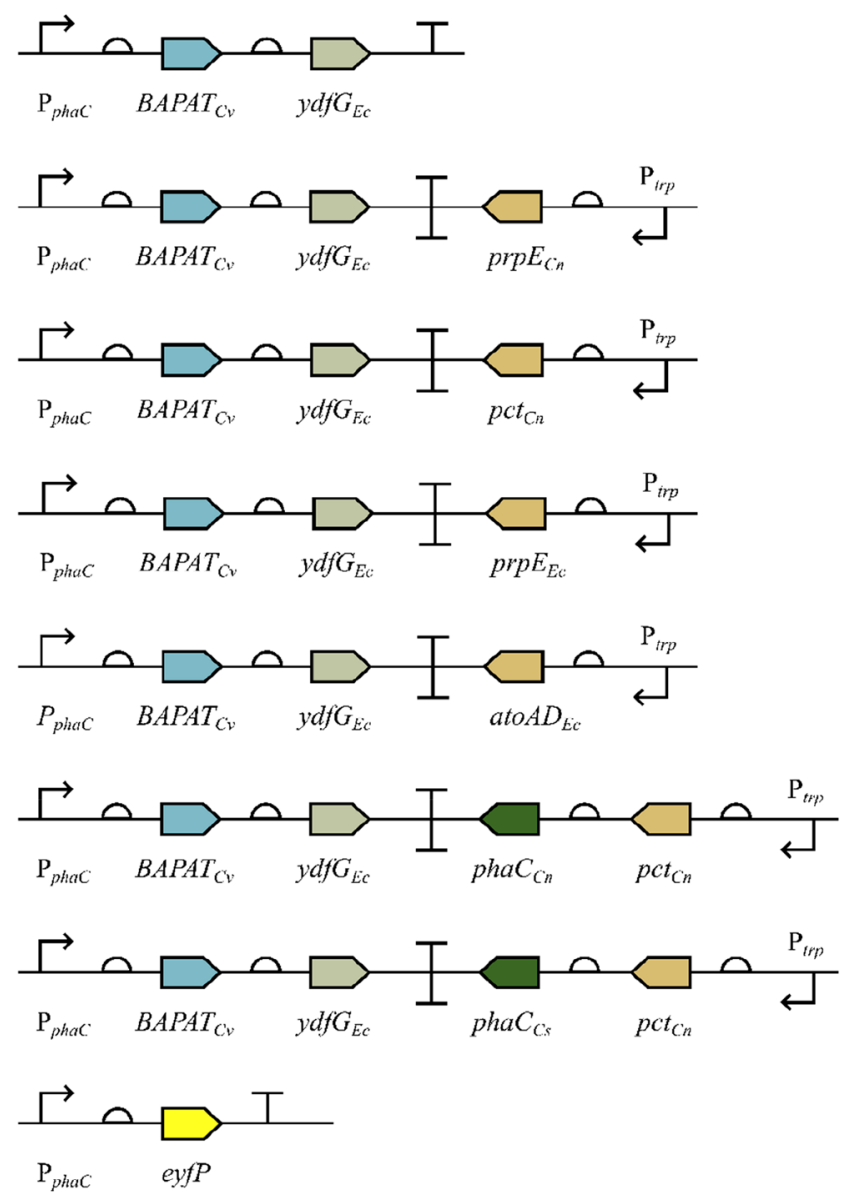

pCNCM0

pCNCM12

pCNCM13

pCNCM14

pCNCM15

pCNCM17

pCNCM21

peyfP

Figure 2. Plasmids tested for the production of poly(3HB-co-3HP). Plasmid pCNCM0 facilitated the conversion of $\beta$-alanine to $3 \mathrm{HP}$. Plasmids pCNCM12-pCNCM15 were constructed to test increased activation of 3HP to 3HP-CoA. Plasmids pCNCM17 and pCNCM21 compared the ability of two PHA synthases to incorporate $3 \mathrm{HP}$ into the copolymer. Plasmid peyfP was used as a control plasmid.

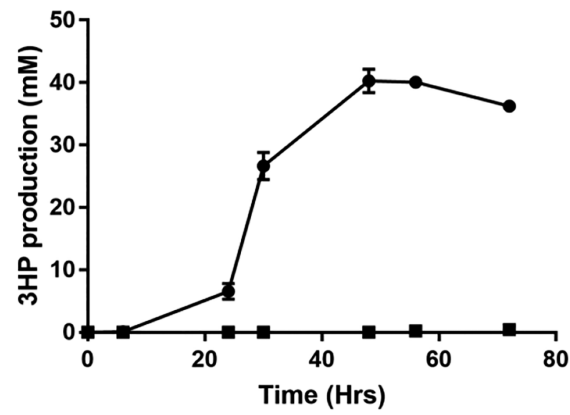

Figure 3. Production of $3 \mathrm{HP}$ from $\beta$-alanine using engineered C. necator H16. $\Delta 3$ _eyfP $(\boldsymbol{\square}), \Delta 3 \_$CNCM0 ( $)$. All data are averages from triplicate experiments.

Table 2. Polymer Produced during Cultivation of Engineered C. necator H16 in Sodium Gluconate SGMM Supplemented with $50 \mathrm{mM} \beta$-Alanine ${ }^{a}$

\begin{tabular}{|lccccc|}
\multicolumn{1}{c}{ strain } & $\begin{array}{c}\text { CDW } \\
(\mathrm{g} / \mathrm{L})\end{array}$ & $\begin{array}{c}\text { PHA } \\
(\text { wt \% })\end{array}$ & $\begin{array}{c}\text { PHA } \\
(\mathrm{g} / \mathrm{L})\end{array}$ & $\begin{array}{c}3 \mathrm{HB} \\
(\mathrm{mol} \%)\end{array}$ & $\begin{array}{c}3 \mathrm{HP} \\
(\mathrm{mol} \%)\end{array}$ \\
\hline 3_eyfP & 4.25 & 71.88 & 3.05 & 100 & - \\
$\Delta$ 3_CNCM0 & 2.00 & 17.74 & 0.35 & 98.73 & 1.27
\end{tabular}

${ }^{a}$ All data are averages from triplicate experiments.

Increasing the Conversion of 3HP to 3HP-CoA. It was seen that strain $\Delta 3{ }_{-} \mathrm{CNCM} 13$, expressing $p c t_{C n}$ as the CoA addiction mechanism, exhibited increased 3HP molar fraction, achieving approximately $11.5 \mathrm{~mol} \% 3 \mathrm{HP}$. This represented a 10 -fold increase in $3 \mathrm{HP}$ molar fraction compared to strain $\Delta 3$ CNCM0. Expression of the propionyl-CoA synthetases of $C$. necator $\mathrm{H} 16$ and $E$. coli in strains $\Delta 3$ CNCM12 and $\triangle 3$ CNCM14, respectively, did not increase 3HP molar fraction, and no growth was observed during cultivation of strain $\triangle 3$ _CNCM15, expressing ato $A D_{E c}$ (Table 3).

Propionyl-CoA synthetases are ATP-dependent. Insufficient availability of ATP under the growth conditions employed offers one explanation as to why the production of these enzymes failed to improve incorporation of $3 \mathrm{HP}$ into the polymer. Alternatively, since these synthetases use free CoA,

Table 3. Impact of Expression of CoA-Addition Mechanism on Composition of Poly(3HB-co-3HP) Produced by Engineered C. necator $\mathrm{H}^{a}{ }^{a}$

\begin{tabular}{cccccc} 
strain & $\begin{array}{c}\text { CDW } \\
(\mathrm{g} / \mathrm{L})\end{array}$ & $\begin{array}{c}\text { PHA } \\
(\text { wt \%) }\end{array}$ & $\begin{array}{l}\text { PHA } \\
(\mathrm{g} / \mathrm{L})\end{array}$ & $\begin{array}{c}3 \mathrm{HB} \\
(\mathrm{mol} \%)\end{array}$ & $\begin{array}{c}3 \mathrm{HP} \\
(\mathrm{mol} \%)\end{array}$ \\
\hline 3_CNCM12 & 3.54 & 34.05 & 1.2 & 98.1 & 1.9 \\
$\Delta$ 3_CNCM13 & 2.81 & 12.81 & 0.36 & 88.5 & 11.5 \\
$\Delta$ 3_CNCM14 & 4.13 & 41.06 & 1.67 & 98.4 & 1.6 \\
$\Delta$ 3_CNCM15 & - & - & - & - & -
\end{tabular}

${ }^{a}$ Strains were cultivated in SGMM supplemented with $50 \mathrm{mM} \beta$ alanine for $48 \mathrm{~h}$. All data are averages from triplicate experiments. 
the availability of this cofactor represents another possible reason as to why the molar ration of $3 \mathrm{HP}$ incorporated in the copolymer was not increased. Strain $\Delta 3$ CNCM15, which received the $E$. coli ato $A D_{E c}$ gene encoding acetoacetyl-CoA acetyltransferase, failed to grow. A similar detrimental effect on the growth of the host was observed following cloning of the propionyl-CoA transferase $\left(\mathrm{Pct}_{\mathrm{Cp}}\right)$ of Clostridium propionicum. ${ }^{57}$ The authors attributed the growth defects to excessive reduction of the intracellular acetyl-CoA pool, as $\mathrm{Pct}_{\mathrm{Cp}}$ can use acetyl-CoA as a CoA donor. Since Ato $\mathrm{AD}_{E c}$ can also use acetylCoA as a CoA donor, its overproduction in strain $\Delta 3 \_C N C M 15$, as a consequence of placing its encoding gene under the control of the strong $\mathrm{P}_{\text {trp }}$ promoter, may similarly explain the growth inhibition observed here. Pct ${ }_{C p}$ has since been used on several occasions for production of $3 \mathrm{HP}$ containing polymers. ${ }^{30,36,56}$ As such it is possible that Ato $\mathrm{AD}_{E c}$ can be used for activation of $3 \mathrm{HP}$ to $3 \mathrm{HP}-\mathrm{CoA}$ provided expression is moderated through the use of a weaker promoter system.

Taken together, of the four different CoA transferases analyzed, the propionyl-CoA transferase of C. necator $\mathrm{H} 16$ was shown to be the most effective means of converting $3 \mathrm{HP}$ to $3 \mathrm{HP}-\mathrm{CoA}$. Its use resulted in a $3 \mathrm{HP}$ molar fraction of $11.5 \mathrm{~mol}$ $\%$ in the PHA copolymer. Nonetheless, the proportion of $3 \mathrm{HP}$ remained relatively low.

Comparison of Two PHA Synthases for Improved $3 \mathrm{HP}$ Incorporation. Strains $\Delta 3 \quad$ CNCM 17 and $\Delta 3$ CNCM21 both produced a copolymer with a dramatically increased $3 \mathrm{HP}$ molar fraction in comparison to strain $\Delta 3 \_C N C M 13$, achieving approximately 77 and $80 \mathrm{~mol} \%$ $3 \mathrm{H} \overline{\mathrm{P}}$, respectively (Table 4). Additionally, the PHA content of the cells and PHA titer were increased relative to strain $\Delta 3$ CNCM13.

Table 4. Impact of the Combined Overproduction of Propionyl-CoA Synthetase and PHA Synthase on the Composition of Poly(3HB-co-3HP) Produced by Engineered C. necator $\mathrm{H}^{\mathrm{a}}$

\begin{tabular}{cccccc} 
strain & $\begin{array}{c}\text { CDW } \\
(\mathrm{g} / \mathrm{L})\end{array}$ & $\begin{array}{c}\text { PHA } \\
(\text { wt \% })\end{array}$ & $\begin{array}{c}\text { PHA } \\
(\mathrm{g} / \mathrm{L})\end{array}$ & $\begin{array}{c}3 \mathrm{HB} \\
(\mathrm{mol} \%)\end{array}$ & $\begin{array}{c}3 \mathrm{HP} \\
(\mathrm{mol} \%)\end{array}$ \\
\hline 3_CNCM17 & 3.33 & 14.30 & 0.47 & 22.66 & 77.34 \\
$\Delta 3$ 3_CNCM21 & 3.96 & 19.27 & 0.76 & 20.29 & 79.71
\end{tabular}

${ }^{a}$ Strains were cultivated in SGMM supplemented with $50 \mathrm{mM} \beta$ alanine for $48 \mathrm{~h}$. All data are averages from triplicate experiments.

It was notable that the use PHA synthase of Chromobacterium sp. USM2 (strain $\Delta 3$ CNCM21) resulted in $60 \%$ more PHA compared to the C. necator H16 synthetase used in strain $\Delta 3$ CNCM17. The difference in PHA titer is most likely attributable to the higher specific activity of the Chromobacterium sp. USM2 PHA synthase. Thus, the Chromobacterium sp. USM2 synthetase has an activity of approximately $238 \mathrm{U} / \mathrm{mg}$, while the PHA synthase of $C$. necator $\mathrm{H} 16$ was measured at 40 $\mathrm{U} / \mathrm{mg} .{ }^{50,58}$ On the basis of this, plasmid pCNCM21 was used in all subsequent experiments.

Production of Poly(3HB-co-3HP) with Different Monomer Compositions. Data from previous studies has shown that modulating the ratio of monomer to polymer in a copolymer can significantly change its properties in terms of, for instance, opacity, transparency, and adhesiveness. ${ }^{59,60}$ Accordingly, the molar fraction of $3 \mathrm{HP}$ in poly(3HB-co$3 \mathrm{HP})$ copolymers has been shown to influence crystallinity, melting temperature, and glass transition temperature. ${ }^{13,19-24}$ Given that $3 \mathrm{HP}$ in strain $\Delta 3$ CNCM21 is produced from $\beta$ alanine, altering the concentration of this amino acid supplement in media provides a simple route to controlling the composition of the copolymer being produced. This was tested by growing $\Delta 3$ CNCM21 in SGMM containing between 0 to $40 \mathrm{mM}$ exogenous $\beta$-alanine. The polymers produced under these conditions contained between 0 and 78 mol \% 3HP (Table 5). Notably, supplementation with $40 \mathrm{mM}$

Table 5. Production of Poly(3HB-co-3HP) with a Range of 3HP Content Following Cultivation of Strain $\Delta 3$ _CNCM21 in SGMM Supplemented with Different Concentrations of $\beta$-Alanine ( \pm Cysteine) for $48 \mathrm{~h}$

$\begin{array}{ccccccr}\begin{array}{c}\beta \text {-alanine } \\ (\mathrm{mM})\end{array} & \begin{array}{c}\text { cysteine } \\ (\mathrm{mM})\end{array} & \begin{array}{c}\text { CDW } \\ (\mathrm{g} / \mathrm{L})\end{array} & \begin{array}{c}\text { PHA } \\ (\text { wt \% })\end{array} & \begin{array}{c}\text { PHA } \\ (\mathrm{g} / \mathrm{L})\end{array} & \begin{array}{c}3 \mathrm{HB} \\ (\mathrm{mol} \%)\end{array} & \begin{array}{c}3 \mathrm{HP} \\ (\mathrm{mol} \%)\end{array} \\ 0 & - & 2.92 & 65.97 & 1.92 & >99.9 & \text { Trace } \\ 5 & - & 4.41 & 60.17 & 2.24 & 97.76 & 2.24 \\ 10 & - & 5.10 & 50.76 & 2.59 & 92.89 & 7.11 \\ 15 & - & 5.31 & 39.24 & 2.08 & 83.4 & 16.60 \\ 20 & - & 4.99 & 29.91 & 1.49 & 63.28 & 36.72 \\ 25 & - & 5.16 & 24.03 & 1.23 & 50.17 & 49.83 \\ 30 & - & 5.03 & 22.16 & 1.11 & 32.99 & 67.01 \\ 40 & - & 4.14 & 16.97 & 0.70 & 21.37 & 78.63 \\ 50^{a} & - & 3.96 & 19.27 & 0.76 & 20.29 & 79.71 \\ 50 & 2 & 4.76 & 17.51 & 0.83 & 11.16 & 88.84\end{array}$

${ }^{a}$ Data taken from Table 4. All data are averages from triplicate experiments.

$\beta$-alanine resulted in approximately the same $3 \mathrm{HP}$ molar fraction as had been achieved when cultures were supplemented with $50 \mathrm{mM} \beta$-alanine. One possible reason for this is that the amount of acetyl-CoA, which is required as the CoA donor molecule for activation of $3 \mathrm{HP}$ to $3 \mathrm{HP}-\mathrm{CoA}$, was insufficient at these higher $\beta$-alanine concentrations.

To attempt to further increase incorporation of $3 \mathrm{HP}$ into the copolymer, it was hypothesized that supplementation with cysteine could be used. Cysteine is a precursor to CoAbiosynthesis and supplementation with this amino acid has previously been used to increase the titers of compounds requiring either $\mathrm{CoA}$ or acetyl-CoA in their biosynthesis, including $\mathrm{PHB} .^{61-64}$ Accordingly, strain $\Delta 3$ CNCM21 was grown in SGMM supplemented with $2 \mathrm{mM}$ cysteine in addition to $50 \mathrm{mM} \beta$-alanine. The poly $(3 \mathrm{HB}-c o-3 \mathrm{HP})$ produced contained $89 \mathrm{~mol} \% 3 \mathrm{HP}$ (Table 5).

Effect of phaA, phaB1, and phaAB1 Deletions on 3HP Content in Copolymer. The preceding experiments demonstrated that a maximum $3 \mathrm{HP}$ content in the polymer of approximately $80 \mathrm{~mol} \%$ was achievable with the most effective enzyme combination and with supplementation of the media with $\beta$-alanine. This could be further increased through the addition of cysteine to the medium (Table 5). One potential strategy for increasing the $3 \mathrm{HP}$ molar fraction without the need for cysteine supplementation would be to reduce flux toward 3HB-CoA biosynthesis. Genome analysis of C. necator $\mathrm{H} 16$ has revealed the presence of at least $15 \beta$ ketothiolases and three acetoacetyl-CoA reductases. ${ }^{38,65,66}$ Previous work has exploited alteration of the phaCAB operon to reduce the capacity of $C$. necator $\mathrm{H} 16$ to produce $3 \mathrm{HB}-\mathrm{CoA}$, thereby favoring incorporation of a second monomer. ${ }^{5,65,67-69}$ Such an approach has previously been exploited for the improved incorporation of 3-hydroxyhexanoate, 3-mercapto- 
propionate, and 3-hydroxyvalerate into growing polymer chains. ${ }^{5,65,67,69}$ To suppress $3 \mathrm{HB}-\mathrm{CoA}$ formation, a range of knockouts targeting the phaCAB operon were therefore generated. Single knockout of the phaA and phaB1 genes resulted in strains $\Delta 3 \mathrm{~A}$ and $\Delta 3 \mathrm{~B} 1$, respectively, while deletion of both phaA and phaB1 produced strain $\triangle 3 \mathrm{AB} 1$ (Figure 4).

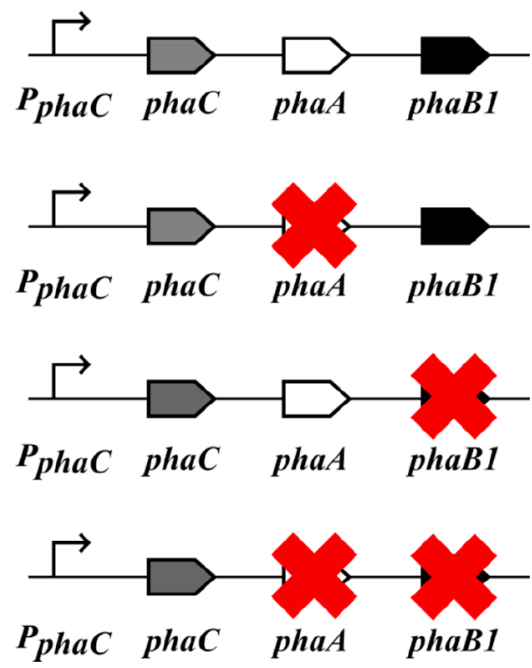

Figure 4. Deletions carried out to suppress formation of 3HB-CoA. From top to bottom; wild-type phaCAB operon, deletion of phaA, deletion of phaB1, deletion of phaA and phaB1.

The effect of the various phaCAB operon alterations is shown in Table 6. In control strains, PHB production was

Table 6. Production of Poly(3HB-co-3HP) by C. necator H16 Strains with Reduced Capacity to Form $3 \mathrm{HB}-\mathrm{CoA}^{a}$

\begin{tabular}{lccccc}
\multicolumn{1}{c}{ strain } & $\begin{array}{c}\text { CDW } \\
(\mathrm{g} / \mathrm{L})\end{array}$ & $\begin{array}{c}\text { PHA } \\
(\text { wt } \%)\end{array}$ & $\begin{array}{c}\text { PHA } \\
(\mathrm{g} / \mathrm{L})\end{array}$ & $\begin{array}{c}3 \mathrm{HB} \\
(\mathrm{mol} \%)\end{array}$ & $\begin{array}{c}3 \mathrm{HP} \\
(\mathrm{mol} \%)\end{array}$ \\
$\Delta$ 3A_CNCM21 & 3.48 & 33.15 & 1.15 & 16.44 & 83.56 \\
$\Delta$ 3B1_CNCM21 & 2.93 & 28.15 & 0.83 & 10.82 & 89.18 \\
$\Delta$ 3AB1_CNCM21 & 3.01 & 29.50 & 0.88 & 8.89 & 91.11 \\
$\Delta$ 3A_eyfP & 3.23 & 72.13 & 2.33 & 100 & 0 \\
$\Delta$ 3B1_eyfP & 2.15 & 18.05 & 0.38 & 100 & 0 \\
$\Delta$ 3AB1_eyfP & 1.86 & 16.04 & 0.30 & 100 & 0
\end{tabular}

${ }^{a}$ Strains were cultivated in SGMM supplemented with $50 \mathrm{mM} \beta$ alanine for $48 \mathrm{~h}$. All data are averages from triplicate experiments.

either slightly or significantly reduced depending on the deletion. Deletion of phaA alone resulted in a minor decrease in $\mathrm{PHB}$ titer. Compared to strain $\Delta 3$ _eyfP, which produced more than $3 \mathrm{~g} / \mathrm{L}$ of $\mathrm{PHB}$, strain $\Delta 3 \mathrm{~A}$ eyfP produced $2.33 \mathrm{~g} / \mathrm{L}$ $\mathrm{PHB}$, although the PHA content of both strains was approximately $70 \%$. In contrast, deletion of phaB1 significantly reduced $\mathrm{PHB}$ titer with strain $\Delta 3 \mathrm{~B} 1$ _eyfP producing only $0.38 \mathrm{~g} / \mathrm{L}$ of PHB. Deletion of both $p \overline{\bar{a}} \bar{A}$ and $p h a B 1$ (strain $\triangle 3 \mathrm{AB} 1$ _eyfP) resulted in a more dramatic outcome, with a decrease in PHA titer to $0.30 \mathrm{~g} / \mathrm{L}$.

As for experimental strains, reducing flux toward $3 \mathrm{HB}-\mathrm{CoA}$ resulted in increased $3 \mathrm{HP}$ molar fraction. Strain $\Delta 3 \mathrm{~A} \_$CNCM21 produced poly $(3 \mathrm{HB}-c o-3 \mathrm{HP})$ with around 84 mol \% 3HP, accounting for approximately 33\% CDW. Additionally, the PHA titer was increased to $1.15 \mathrm{~g} / \mathrm{L}$. Further increases in $3 \mathrm{HP}$ molar fraction were observed in strains containing a phaB1 deletion, although PHA content and titer was reduced in comparison to the phaA knockout strain. Strain $\triangle 3 \mathrm{~B} 1$ CNCM21 produced a copolymer containing $89 \mathrm{~mol} \%$ $3 \mathrm{HP}$, whereas strain $\triangle 3 \mathrm{AB} 1$ CNCM21 produced a copolymer with $91 \mathrm{~mol} \% 3 \mathrm{HP}$. Prior to this, the highest molar fraction of $3 \mathrm{HP}$ achieved was $89 \mathrm{~mol} \% 3 \mathrm{HP}$ through supplementation of the media with $2 \mathrm{mM}$ cysteine.

Reducing the capacity of $C$. necator $\mathrm{H} 16$ to produce $3 \mathrm{HB}$ $\mathrm{CoA}$ therefore resulted in further enhancement of $3 \mathrm{HP}$ molar fraction in the copolymer. Suppressing acetyl-CoA flux toward $\mathrm{PHB}$ biosynthesis could have also increased the acetyl-CoA pool available for activation of $3 \mathrm{HP}$ to $3 \mathrm{HP}-\mathrm{CoA}$ by $\mathrm{Pct}_{\mathrm{Cn}}$ as a secondary benefit. It was reported that increased acetyl-CoA availability following deletion of phaA resulted in greater $3 \mathrm{HHx}$ content when $C$. necator $\mathrm{H} 16$ was engineered to produce poly(3HB-co-3HHx). ${ }^{69}$ Excluding those already described in the phaCAB operon, at least 14 homologues of phaA and two homologues of phaBl have been identified in C. necator H16, indicating a significant capacity for 3HB-CoA biosynthesis. ${ }^{65,66}$ Despite this, deletion of phaA or phaB1 either individually or together resulted in an increase in $3 \mathrm{HP}$ content in the copolymer.

Previous studies have shown phaB3, a homologue of phaB1, is only active under certain growth conditions, while phaB2 is inactive. For example, although a phaB1 deletion strain was capable of producing $\mathrm{PHB}$ during growth on fructose as a consequence of possessing a functional phaB3 gene, PhaB3 activity was not detected during growth on trioleate or palm oil. $^{66,70}$ It was also shown that upregulation of phaB3 occurred when $C$. necator $\mathrm{H} 16$ was cultivated in gluconate supplemented with $3,3^{\prime}$-thiodipropionic acid, compared to gluconate alone. ${ }^{71}$ Deletion of all three phaB homologues results in accumulation of less than $20 \%$ of CDW as PHA. $^{66}$ During growth on gluconate in the course of this work, strains lacking phaB1 also accumulated less than 20\% CDW (Table 6). In the conditions tested, phaB3 is, therefore, presumed to be inactive.

Production of Poly(3HB-co-3HP) from Batch Cultivation. Of all the recombinant strains tested so far, strain $\triangle 3 \mathrm{~A} C N C M 21$ had exhibited a good balance of PHA content and $\overline{\mathrm{PH}} \mathrm{H}$ titer along with high $3 \mathrm{HP}$ molar fraction. As such, it was chosen to cultivate strain $\triangle 3 \mathrm{~A}$ CNCM 21 in a bioreactor to further investigate the results obtained during the flask cultivation. Strain $\Delta 3 \mathrm{~A} \_\mathrm{CNCM} 21$ was therefore cultivated in a $2.5 \mathrm{~L}$ bioreactor using SGMM supplemented with $50 \mathrm{mM} \beta$ alanine as before.

Following $42 \mathrm{~h}$ of cultivation, cell dry weight (CDW) reached $6.25 \mathrm{~g} / \mathrm{L}$ of which $25.54 \%$ (wt \%) was PHA, corresponding to a PHA titer of $1.6 \mathrm{~g} / \mathrm{L}$. Additionally, the poly(3HB-co-3HP) copolymer produced by strain $\Delta 3 \mathrm{~A} \_\mathrm{CNCM} 21$ contained approximately $91.19 \mathrm{~mol} \% 3 \mathrm{HP}$. This was higher than strain $\triangle 3 \mathrm{~A} \_$CNCM21 had achieved from flask cultivation and was equivalent to the $3 \mathrm{HP}$ content of the copolymer produced by strain $\triangle 3 \mathrm{AB} 1 \_$CNCM 21 .

\section{CONCLUSION}

In the present study we demonstrated that it is possible to engineer $C$. necator $\mathrm{H} 16$ to produce a poly $(3 \mathrm{HB}-c o-3 \mathrm{HP})$ polymer through the overexpression of genes encoding the enzymes necessary to convert exogenously supplied $\beta$-alanine into 3HP. Although the two enzymes used, a $\beta$-alanine pyruvate aminotransferase (BAPAT) from C. violaceum and an E. coli NADP-dependent 3-hydroxyacid dehydrogenase (ydfG), catalyzed the production of approximately $40 \mathrm{mM}$ $3 \mathrm{HP}$ from $50 \mathrm{mM} \beta$-alanine, only $1.27 \mathrm{~mol} \% 3 \mathrm{HP}$ was 
incorporated into the polymer. The $3 \mathrm{HP}$ molar fraction could be increased by either the overexpression of pivotal genes involved either in the conversion of $3 \mathrm{HP}$ to $3 \mathrm{HP}-\mathrm{CoA}$ (propionyl-CoA transferase) or the synthesis of PHA itself (PHA synthase), the inclusion of additional media supplements (cysteine), or the suppression of $3 \mathrm{HB}-\mathrm{CoA}$ biosynthesis by appropriate gene deletion. Through a combination of all these measures it was possible to produce poly (3HB-co-3HP) copolymers containing over $80 \mathrm{~mol} \% 3 \mathrm{HP}$, with the highest 3HP molar fraction achieved being $91 \mathrm{~mol} \% 3 \mathrm{HP}$.

Nonetheless, PHA content and titer were relatively low, and decreased as $3 \mathrm{HP}$ content of the copolymer increased. Low PHA yield is a key limiting factor to commercialization of PHAs as an alternative to traditional plastics. ${ }^{72}$ Previous research has shown that PHA titer can be increased by a range of strategies including engineering of promoters, ribosomal binding sites, cell morphology, and PHA synthase substrate specificity. ${ }^{8,73-76}$ Future work therefore could be focused on increasing the PHA content and titer of the cells by employing a variety of the approaches mentioned.

In this study, only the downstream part of the $\beta$-alanine pathway was investigated, and $\beta$-alanine was supplied exogenously rather than derived from the TCA cycle. While this approach was sufficient for our purposes, supplementation of $\beta$-alanine at large scale will add to copolymer production costs. An alternative solution is to develop the upstream part of the $\beta$-alanine pathway, in which $\beta$-alanine can be derived from the TCA cycle. Previously this approach has been used to overproduce $\beta$-alanine using recombinant E. coli. ${ }^{77}$ By combining the upstream and downstream parts of the $\beta$ alanine pathway, it is then possible to produce $3 \mathrm{HP}$ and $3 \mathrm{HP}$ containing copolymers from a range of carbon sources without the need to provide exogenous $\beta$-alanine. ${ }^{28,40-42}$ Previously, it has been shown that $C$. necator $\mathrm{H} 16$ is capable of growing on a wide array of carbon sources, including various waste streams such as used cooking oil, spent coffee grounds, and $\mathrm{CO}_{2}$-rich off gases. ${ }^{78-80}$ As such a future strain of $C$. necator $\mathrm{H} 16$, which has been engineered to overproduce $\beta$-alanine and therefore $3 \mathrm{HP}$ from the TCA cycle, could theoretically produce poly(3HB-co-3HP) from sources such as $\mathrm{CO}_{2}$ without the need to supplement $\beta$-alanine. Use of waste carbon sources is expected to decrease the cost of PHA production in comparison to using more expensive and highly refined carbon sources such as sugars. ${ }^{14}$ To that end and to avoid supplementation of $\beta$-alanine, subsequent work will focus on increasing the supply of $\beta$-alanine from the TCA cycle.

\section{MATERIALS AND METHODS}

Microorganisms, Plasmids, and Genetic Methods. General cultivation of $C$. necator $\mathrm{H} 16$ was carried out in lysogeny broth (LB) at $30^{\circ} \mathrm{C}$. E. coli was cultivated in LB at 37 ${ }^{\circ} \mathrm{C}$. When acting as a recipient during conjugation, $\mathrm{C}$. necator $\mathrm{H} 16$ was cultivated in low-salt LB medium. ${ }^{81}$ Where necessary, tetracycline was added to a concentration of $15 \mu \mathrm{g} / \mathrm{mL}$ for both $E$. coli and C. necator $\mathrm{H16}$, and gentamycin was added to a concentration of $10 \mu \mathrm{g} / \mathrm{mL}$ for $C$. necator $\mathrm{H} 16$ cultivations.

All strains and plasmids used are listed in Table S1. The nucleotide sequence of plasmids pCNCM0, pCNCM12, pCNCM13, pCNCM14, pCNCM15, pCNCM17, pCNCM21, pCNCM_phaA, pCNCM_phaB1, and pCNCM phaAB1 have been deposited in the public version of the JBEI registry (https://public-registry.jbei.org) under the accession numbers JPUB_018762, JPUB_018763,
JPUB_018764, JPUB_018765, JPUB_018766, JPUB_018767, JPUB_018768, JPUB_018769, JPUB_018770, and JPUB_- 018771 , respectively. The PHA synthase from Chromobacterium sp. USM2 was synthesized without codon optimization by Genscript Biotech (Leiden, Netherlands) Supporting Information.

PCR was performed using Q5 High-Fidelity $2 \times$ Master Mix (NEB) and GoTaq Green Master Mix (Promega) according to the manufacturers' protocol. Q5 High-Fidelity $2 \times$ Master Mix was used for amplification of sequences for cloning, while GoTaq Green Master Mix was used for screening purposes. Assembly of plasmids was carried out using NEBuilder HiFi DNA Assembly Master Mix (New England BioLabs Inc. (NEB)). Plasmid DNA was isolated using the Monarch Plasmid Miniprep Kit (NEB). Restriction enzymes were purchased from NEB and Thermo Fisher Scientific. Gelpurified PCR products were extracted using the Monarch DNA Gel Extraction Kit (NEB). Chemically competent E. coli were transformed via heat shock. ${ }^{82}$ Plasmids were transferred to C. necator $\mathrm{H} 16$ via conjugation using E. coli $\mathrm{S} 17-1$ as a donor strain. $^{81}$

Knockout plasmids were constructed using a suicide vector encoding a copy of the $s a c B$ gene to allow for counter-selection using sucrose. Approximately $700 \mathrm{bp}$ of the upstream and downstream regions flanking the gene of interest were amplified and assembled into a deletion cassette using the HiFi DNA Assembly Kit (NEB).

HPLC Analysis of 3HP, PHA Production, and Characterization. 3HP concentration in the supernatant was determined by HPLC using a previously described method. ${ }^{54}$

Engineered strains of $C$. necator $\mathrm{H} 16$ were streaked on solid SGMM agar containing tetracycline. From these plates, precultures were prepared in $50 \mathrm{~mL}$ Falcon tubes containing $5 \mathrm{~mL}$ LB medium supplemented with tetracycline. The precultures were grown overnight at $30{ }^{\circ} \mathrm{C}$ with shaking at $200 \mathrm{rpm}$. Production of PHA by engineered strains of C. necator $\mathrm{H} 16$ was carried out in $250 \mathrm{~mL}$ Erlenmeyer flasks containing $30 \mathrm{~mL}$ of sodium gluconate minimal medium (SGMM) supplemented with $\beta$-alanine. In all experiments, overnight precultures were used to inoculate flasks to a starting $\mathrm{OD}_{600}$ of 0.05 . In all experiments, SGMM was supplemented with $50 \mathrm{mM} \beta$-alanine, unless otherwise stated.

Batch cultivation was carried out in a $2.5 \mathrm{~L}$ bioreactor (New Brunswick BioFlo/CelliGen 115, Eppendorf AG, Hamburg, Germany) with a working volume of $1.5 \mathrm{~L}$. SGMM supplemented with $50 \mathrm{mM} \beta$-alanine was used as the culture medium. Culture conditions were maintained as follows: temperature was maintained at $30^{\circ} \mathrm{C}, \mathrm{pH}$ 6.9, and dissolved oxygen concentration at $30 \%$.

SGMM was composed of $2 \%$ sodium gluconate $(\mathrm{w} / \mathrm{v})$, $\mathrm{Na}_{2} \mathrm{HPO}_{4} \cdot 12 \mathrm{H}_{2} \mathrm{O} 9 \mathrm{~g} / \mathrm{L}, \mathrm{KH}_{2} \mathrm{PO}_{4} 1.5 \mathrm{~g} / \mathrm{L}, \mathrm{NH}_{4} \mathrm{Cl} 0.5 \mathrm{~g} / \mathrm{L}$, $\mathrm{MgSO}_{4} \cdot 7 \mathrm{H}_{2} \mathrm{O} 0.2 \mathrm{~g} / \mathrm{L}, \mathrm{CaCl}_{2} \cdot 2 \mathrm{H}_{2} \mathrm{O} 20 \mathrm{mg} / \mathrm{L}, \mathrm{Fe}(\mathrm{III}) \mathrm{NH}_{4^{-}}$ citrate $1.2 \mathrm{mg} / \mathrm{L}$, and trace element solution (SL7) $1 \mathrm{~mL} / \mathrm{L}$. SL7 was prepared to the following composition; 25\% (w/v) $\mathrm{HCl} 1.3 \mathrm{~mL} / \mathrm{L}, \mathrm{H}_{3} \mathrm{BO}_{3} 62 \mathrm{mg} / \mathrm{L}, \mathrm{CoCl}_{2} \cdot 6 \mathrm{H}_{2} \mathrm{O} 190 \mathrm{mg} / \mathrm{L}$, $\mathrm{CuCl}_{2} \cdot 2 \mathrm{H}_{2} \mathrm{O} 17 \mathrm{mg} / \mathrm{L}, \mathrm{MnCl}_{2} \cdot 4 \mathrm{H}_{2} \mathrm{O} 100 \mathrm{mg} / \mathrm{L}, \mathrm{Na}_{2} \mathrm{MoO}_{4}$. $2 \mathrm{H}_{2} \mathrm{O} 36 \mathrm{mg} / \mathrm{L}, \mathrm{NiCl}_{2} \cdot 6 \mathrm{H}_{2} \mathrm{O} 24 \mathrm{mg} / \mathrm{L}$, and $\mathrm{ZnCl}_{2} 70 \mathrm{mg} / \mathrm{L}$. The $\mathrm{pH}$ was adjusted to 6.9. Engineered strains of $\mathrm{C}$. necator $\mathrm{H} 16$ were cultivated aerobically at $30{ }^{\circ} \mathrm{C}$ with shaking at 200 rpm.

Bacterial culture was centrifuged and washed prior to lyophilization, after which the cell dry weight was measured. 
The PHA content of the cells was determined by gas chromatography/mass spectrometry after propanolysis in chloroform (Agilent Technologies, GC 6890N, MS5 973N).

\section{- ASSOCIATED CONTENT}

\section{SI Supporting Information}

The Supporting Information is available free of charge at https://pubs.acs.org/doi/10.1021/acssynbio.1c00283.

Further details on knockout plasmid construction and DNA sequence of the PHA synthase from Chromobacterium sp. USM2 (PDF)

\section{AUTHOR INFORMATION}

\section{Corresponding Author}

Katalin Kovács - BBSRC/EPSRC Synthetic Biology Research Centre, The University of Nottingham, Nottingham NG7 2RD, U.K.; School of Pharmacy, The University of Nottingham, Nottingham NG7 2RD, U.K.; (1) orcid.org/ 0000-0002-0622-940X; Email: katalin.kovacs@ nottingham.ac.uk

\section{Authors}

Callum McGregor - BBSRC/EPSRC Synthetic Biology Research Centre, The University of Nottingham, Nottingham NG7 2RD, U.K.; (1) orcid.org/0000-0003-2551-8044

Nigel P. Minton - BBSRC/EPSRC Synthetic Biology Research Centre, The University of Nottingham, Nottingham NG7 2RD, U.K.; () orcid.org/0000-0002-9277-1261

Complete contact information is available at: https://pubs.acs.org/10.1021/acssynbio.1c00283

\section{Author Contributions}

C.M. and K.K. designed the study. C.M. performed the experiments. C.M., K.K., and N.P.M. analyzed the data and wrote the manuscript.

\section{Notes}

The authors declare no competing financial interest.

\section{ACKNOWLEDGMENTS}

This work was supported by the Biotechnology and Biological Sciences Research Council [Grant Number BB/L013940/1] (BBSRC). We thank the Nottingham-Rothamstead Doctoral Training Partnership for providing a studentship to C.M. [Grant Number BB/M008770/1]. We thank Matthew Abbott and James Fothergill for assistance with HPLC and GC-MS analysis.

\section{REFERENCES}

(1) Geyer, R.; Jambeck, J. R.; Law, K. L. Production, use, and fate of all plastics ever made. Science Advances. 2017, 3 (7), 25-29.

(2) Lee, S. Y. Bacterial Polyhydroxyalkanoates. Biotechnol. Bioeng. 1996, 49, $1-14$.

(3) Helm, J.; Wendlandt, K. D.; Jechorek, M.; Stottmeister, U. Potassium deficiency results in accumulation of ultra-high molecular weight poly- $\beta$-hydroxybutyrate in a methane-utilizing mixed culture. $J$. Appl. Microbiol. 2008, 105 (4), 1054-1061.

(4) Ishizaki, A.; Tanaka, K.; Taga, N. Microbial production of polyD-3-hydroxybutyrate from CO2x. Appl. Microbiol. Biotechnol. 2001, 57 (1-2), 6-12.

(5) Budde, C. F.; Riedel, S. L.; Willis, L. B.; Rha, C. K.; Sinskey, A. J. Production of poly(3-hydroxybutyrate-co-3-hydroxyhexanoate) from plant oil by engineered Ralstonia eutropha strains. Appl. Environ. Microbiol. 2011, 77 (9), 2847-2854.
(6) Insomphun, C.; Mifune, J.; Orita, I.; Numata, K.; Nakamura, S.; Fukui, T. Modification of $\beta$-oxidation pathway in Ralstonia eutropha for production of poly(3-hydroxybutyrate-co-3-hydroxyhexanoate) from soybean oil. J. Biosci. Bioeng. 2014, 117 (2), 184-190.

(7) Park, S. J.; Jang, Y. A.; Noh, W.; Oh, Y. H.; Lee, H.; David, Y.; Baylon, M. G.; Shin, J.; Yang, J. E.; Choi, S. Y.; Lee, S. H.; Lee, S. Y. Metabolic engineering of Ralstonia eutropha for the production of polyhydroxyalkanoates from sucrose. Biotechnol. Bioeng. 2015, 112 (3), 638-643.

(8) Shen, R.; Yin, J.; Ye, J. W.; Xiang, R. J.; Ning, Z. Y.; Huang, W. Z.; Chen, G. Q. Promoter Engineering for Enhanced P(3HB- co4HB) Production by Halomonas bluephagenesis. ACS Synth. Biol. 2018, 7 (8), 1897-1906.

(9) Peoples, O. P.; Sinskey, A. J. Poly- $\beta$-hydroxybutyrate (PHB) biosynthesis in Alcaligenes eutrophus H16. Identification and characterization of the PHB polymerase gene (phbC). J. Biol. Chem. 1989, 264 (26), 15298-303.

(10) Lee, S. Y.; Yim, K. S.; Chang, H. N.; Chang, Y. K. Construction of plasmids, estimation of plasmid stability, and use of stable plasmids for the production of poly(3-hydroxybutyric acid) by recombinant Escherichia coli. J. Biotechnol. 1994, 32 (2), 203-11.

(11) Holmes, P. A. Applications of PHB - A microbially produced biodegradable thermoplastic. Phys. Technol. 1985, 16 (1), 32-6.

(12) Kunioka, M.; Doi, Y. Thermal Degradation of Microbial Copolyesters: Poly(3-hydroxybutyrate-co-3-hydroxyvalerate) and Poly(3-hydroxybutyrate-co-4-hydroxybutyrate). Macromolecules 1990, 23 (7), 1933-6.

(13) Shimamura, E.; Scandola, M.; Doi, Y. Microbial Synthesis and Characterization of Poly(3-hydroxybutyrate-co-3-hydroxypropionate). Macromolecules 1994, 27 (16), 4429-35.

(14) Choi, S. Y.; Rhie, M. N.; Kim, H. T.; Joo, J. C.; Cho, I. J.; Son, J.; Jo, S. Y.; Sohn, Y. J.; Baritugo, K. A.; Pyo, J.; Lee, Y.; Lee, S. Y.; Park, S. J. Metabolic engineering for the synthesis of polyesters: A 100 -year journey from polyhydroxyalkanoates to non-natural microbial polyesters. Metab. Eng. 2020, 58, 47-81.

(15) Rehm, B. H. A. Polyester synthases: Natural catalysts for plastics. Biochem. J. 2003, 376 (1), 15-33.

(16) Fukui, T.; Suzuki, M.; Tsuge, T.; Nakamura, S. Microbial synthesis of poly((R)-3-hydroxybutyrate-co- 3-hydroxypropionate) from unrelated carbon sources by engineered cupriavidus necator. Biomacromolecules 2009, 10 (4), 700-6.

(17) Choi, J Il; Lee, S. Y.; Shin, K.; Lee, W. G.; Park, S. J.; Chang, H. N.; Chang, Y. K. Pilot scale production of pory(3-hydroxybutyrate-co3-hydroxyvalerate) by fed-batch culture of recombinant Escherichia coli. Biotechnol. Bioprocess Eng. 2002, 7 (6), 371-4.

(18) Jeon, J. M.; Brigham, C. J.; Kim, Y. H.; Kim, H. J.; Yi, D. H.; Kim, H.; Rha, C. K.; Sinskey, A. J.; Yang, Y. H. Biosynthesis of poly(3hydroxybutyrate-co-3-hydroxyhexanoate) ( $\mathrm{P}(\mathrm{HB}-\mathrm{co}-\mathrm{HHx})$ ) from butyrate using engineered Ralstonia eutropha. Appl. Microbiol. Biotechnol. 2014, 98 (12), 5461-9.

(19) Nakamura, S.; Kunioka, M.; Doi, Y. Biosynthesis and characterization of bacterial poly (3-hydroxybutyrate-co-3-hydroxypropionate). J. Macromol. Sci., Chem. 1991, 28 (1), 15-24.

(20) Hiramitsu, M.; Doi, Y. Microbial synthesis and characterization of poly(3-hydroxybutyrate-co-3-hydroxypropionate). Polymer 1993, 34 (22), 4782-6.

(21) Ichikawa, M.; Nakamura, K.; Yoshie, N.; Asakawa, N.; Inoue, Y.; Doi, Y. Morphological study of bacterial poly(3-hydroxybutyrateco-3-hydroxypropionate). Macromol. Chem. Phys. 1996, 197 (8), 2467-80.

(22) Cao, A.; Ichikawa, M.; Kasuya, K. I.; Yoshie, N.; Asakawa, N.; Inoue, Y.; Doi, Y.; Abe, H. Composition fractionation and thermal characterization of poly(3-hydroxybutyrate-co-3-hydroxypropionate). Polym. J. 1996, 28 (12), 1096-102.

(23) Cao, A.; Kasuya, K. I.; Abe, H.; Doi, Y.; Inoue, Y. Studies on comonomer compositional distribution of the bacterial poly(3hydroxybutyric acid-co-3-hydroxypropionic acid)s and crystal and thermal characteristics of their fractionated component copolyesters. Polymer 1998, 39 (20), 4801-16. 
(24) Arai, Y.; Cao, A.; Yoshie, N.; Inoue, Y. Studies on comonomer compositional distribution and its effect on some physical properties of bacterial poly(3-hydroxybutyric acid-co-3-hydroxypropionic acid). Polym. Int. 1999, 48 (12), 1219-28.

(25) Andreeßen, B.; Steinbüchel, A. Biosynthesis and biodegradation of 3-hydroxypropionate-containing polyesters. Appl. Environ. Microbiol. 2010, 76 (15), 4919-25.

(26) Zhou, Q.; Shi, Z. Y.; Meng, D. C.; Wu, Q.; Chen, J. C.; Chen, G. Q. Production of 3-hydroxypropionate homopolymer and poly(3hydroxypropionate-co-4-hydroxybutyrate) copolymer by recombinant Escherichia coli. Metab. Eng. 2011, 13 (6), 777-85.

(27) Wang, Q.; Yang, P.; Xian, M.; Yang, Y.; Liu, C.; Xue, Y.; Zhao, G. Biosynthesis of poly(3-hydroxypropionate-co-3-hydroxybutyrate) with fully controllable structures from glycerol. Bioresour. Technol. 2013, 142, 741-4.

(28) Wang, Q.; Yang, P.; Xian, M.; Feng, L.; Wang, J.; Zhao, G. Metabolic engineering of escherichia coli for poly(3-hydroxypropionate) production from glycerol and glucose. Biotechnol. Lett. 2014, 36 (11), 2257-62.

(29) Meng, D. C.; Wang, Y.; Wu, L. P.; Shen, R.; Chen, J. C.; Wu, Q.; Chen, G. Q. Production of poly(3-hydroxypropionate) and poly(3-hydroxybutyrate-co-3-hydroxypropionate) from glucose by engineering Escherichia coli. Metab. Eng. 2015, 29, 189-95.

(30) Sato, S.; Andreeßen, B.; Steinbüchel, A. Strain and process development for poly(3HB-co-3HP) fermentation by engineered Shimwellia blattae from glycerol. AMB Express 2015, DOI: 10.1186/ s13568-015-0105-8.

(31) Andreeßen, B.; Lange, A. B.; Robenek, H.; Steinbüchel, A. Conversion of glycerol to poly(3-hydroxypropionate) in recombinant escherichia coli. Appl. Environ. Microbiol. 2010, 76 (2), 622-6.

(32) Leal, N. A.; Havemann, G. D.; Bobik, T. A. PduP is a coenzyme-a-acylating propionaldehyde dehydrogenase associated with the polyhedral bodies involved in B12-dependent 1,2-propanediol degradation by Salmonella enterica serovar Typhimurium LT2. Arch. Microbiol. 2003, 180 (5), 353-61.

(33) Wang, Q.; Yang, P.; Liu, C.; Xue, Y.; Xian, M.; Zhao, G. Biosynthesis of poly(3-hydroxypropionate) from glycerol by recombinant Escherichia coli. Bioresour. Technol. 2013, 131, 548-51.

(34) Gao, Y.; Liu, C.; Ding, Y.; Sun, C.; Zhang, R.; Xian, M.; Zhao, G. Development of genetically stable Escherichia coli strains for poly(3-hydroxypropionate) production. PLoS One 2014, 9 (5), 1-9.

(35) Linares-Pastén, J. A.; Sabet-Azad, R.; Pessina, L.; Sardari, R. R. R.; Ibrahim, M. H. A.; Hatti-Kaul, R. Efficient poly(3-hydroxypropionate) production from glycerol using Lactobacillus reuteri and recombinant Escherichia coli harboring L. reuteri propionaldehyde dehydrogenase and Chromobacterium sp. PHA synthase genes. Bioresour. Technol. 2015, 180, 172-6.

(36) Heinrich, D.; Andreessen, B.; Madkour, M. H.; Al-Ghamdi, M. A.; Shabbaj, I. I.; Steinbüchel, A. From waste to plastic: Synthesis of poly(3-hydroxypropionate) in: Shimwellia blattae. Appl. Environ. Microbiol. 2013, 79 (12), 3582-9.

(37) Feng, X.; Xian, M.; Liu, W.; Xu, C.; Zhang, H.; Zhao, G. Biosynthesis of poly(3-hydroxypropionate) from glycerol using engineered Klebsiella pneumoniae strain without vitamin B12. Bioengineered. 2015, 6 (2), 77-81.

(38) Pohlmann, A.; Fricke, W. F.; Reinecke, F.; Kusian, B.; Liesegang, H.; Cramm, R.; Eitinger, T.; Ewering, C.; Pötter, M.; Schwartz, E.; Strittmatter, A.; Voß, I.; Gottschalk, G.; Steinbüchel, A.; Friedrich, B.; Bowien, B. Genome sequence of the Bioplasticproducing "Knallgas" bacterium Ralstonia eutropha H16. Nat. Biotechnol. 2006, 24 (10), 1257-62.

(39) Wang, Q.; Liu, C.; Xian, M.; Zhang, Y.; Zhao, G. Biosynthetic pathway for poly(3-Hydroxypropionate) in recombinant Escherichia coli. J. Microbiol. 2012, 50 (4), 693-7.

(40) Borodina, I.; Kildegaard, K. R.; Jensen, N. B.; Blicher, T. H.; Maury, J.; Sherstyk, S.; Schneider, K.; Lamosa, P.; Herrgård, M. J.; Rosenstand, I.; Öberg, F.; Forster, J.; Nielsen, J. Establishing a synthetic pathway for high-level production of 3-hydroxypropionic acid in Saccharomyces cerevisiae via $\beta$-alanine. Metab. Eng. 2015, 27, $57-64$.

(41) Song, C. W.; Kim, J. W.; Cho, I. J.; Lee, S. Y. Metabolic Engineering of Escherichia coli for the Production of 3-Hydroxypropionic Acid and Malonic Acid through $\beta$-Alanine Route. ACS Synth. Biol. 2016, 5 (11), 1256-63.

(42) Lacmata, S. T.; Kuiate, J. R.; Ding, Y.; Xian, M.; Liu, H.; Boudjeko, T.; Feng, X.; Zhao, G. Enhanced poly(3-hydroxypropionate) production via $\beta$-alanine pathway in recombinant Escherichia coli. PLoS One 2017, 12 (3), 1-11.

(43) Valentin, H. E.; Mitsky, T. A.; Mahadeo, D. A.; Tran, M.; Gruys, K. J. Application of a propionyl coenzyme A synthetase for poly(3-hydroxypropionate-co-3-hydroxybutyrate) accumulation in recombinant Escherichia coli. Appl. Environ. Microbiol. 2000, 66 (12), 5253-8.

(44) Lindenkamp, N.; Schürmann, M.; Steinbüchel, A. A propionate CoA-transferase of Ralstonia eutropha $\mathrm{H} 16$ with broad substrate specificity catalyzing the CoA thioester formation of various carboxylic acids. Appl. Microbiol. Biotechnol. 2013, 97 (17), 7699-709.

(45) Volodina, E.; Schürmann, M.; Lindenkamp, N.; Steinbüchel, A. Characterization of propionate CoA-transferase from Ralstonia eutropha H16. Appl. Microbiol. Biotechnol. 2014, 98 (8), 3579-89.

(46) Zhuang, Q.; Qi, Q. Engineering the pathway in Escherichia coli for the synthesis of medium-chain-length polyhydroxyalkanoates consisting of both even- and odd-chain monomers. Microb. Cell Fact. 2019, 18 (1), 135.

(47) Yang, J. E.; Choi, Y. J.; Lee, S. J.; Kang, K.-H.; Lee, H.; Oh, Y. H.; Lee, S. H.; Park, S. J.; Lee, S. Y. Metabolic engineering of Escherichia coli for biosynthesis of poly(3-hydroxybutyrate-co-3hydroxyvalerate) from glucose. Appl. Microbiol. Biotechnol. 2014, 98 (1), 95-104.

(48) Jeon, J.-M.; Kim, H.-J.; Bhatia, S. K.; Sung, C.; Seo, H.-M.; Kim, J.-H.; Park, H.-Y.; Lee, D.; Brigham, C. J.; Yang, Y.-H. Application of acetyl-CoA acetyltransferase (AtoAD) in Escherichia coli to increase 3-hydroxyvalerate fraction in poly(3-hydroxybutyrate-co-3-hydroxyvalerate). Bioprocess Biosyst. Eng. 2017, 40 (5), 781-9.

(49) Arikawa, H.; Matsumoto, K. Evaluation of gene expression cassettes and production of poly(3-hydroxybutyrate-co-3-hydroxyhexanoate) with a fine modulated monomer composition by using it in Cupriavidus necator. Microb. Cell Fact. 2016, 15 (1), 184.

(50) Yuan, W.; Jia, Y.; Tian, J.; Snell, K. D.; Müh, U.; Sinskey, A. J.; Lambalot, R. H.; Walsh, C. T.; Stubbe, J. A. Class I and III polyhydroxyalkanoate synthases from Ralstonia eutropha and Allochromatium vinosum: Characterization and substrate specificity studies. Arch. Biochem. Biophys. 2001, 394 (1), 87-98.

(51) Song, J. J.; Zhang, S.; Lenz, R. W.; Goodwin, S. In vitro polymerization and copolymerization of 3-hydroxypropionyl-CoA with the PHB synthase from Ralstonia eutropha. Biomacromolecules 2000, 1 (3), 433-9.

(52) Grant, S. G. N.; Jessee, J.; Bloom, F. R.; Hanahan, D. Differential plasmid rescue from transgenic mouse DNAs into Escherichia coli methylation-restriction mutants. Proc. Natl. Acad. Sci. U. S. A. 1990, 87 (12), 4645-9.

(53) Simon, R.; Priefer, U.; Puehler, A. A Broad Host Range Mobilization System for In Vivo Genetic Engineering: Transposon Mutagenesis in Gram Negative Bacteria. Bio/Technology 1983, 1, 784-91.

(54) Arenas-López, C.; Locker, J.; Orol, D.; Walter, F.; Busche, T.; Kalinowski, J.; Minton, N. P.; Kovács, K.; Winzer, K. The genetic basis of 3-hydroxypropanoate metabolism in Cupriavidus necator H16. Biotechnol. Biofuels 2019, 12 (1), 150.

(55) Ehsaan, M.; Baker, J.; Kovács, K.; Malys, N.; Minton, N. P. The pMTL7000 modular, plasmid vector series for strain engineering in Cupriavidus necator H16. J. Microbiol. Methods 2021, 189, 106323.

(56) Andreeßen, B.; Johanningmeier, B.; Burbank, J.; Steinbüchel, A. Influence of the operon structure on poly(3-hydroxypropionate) synthesis in Shimwellia blattae. Appl. Microbiol. Biotechnol. 2014, 98 (17), 7409-22. 
(57) Selmer, T.; Willanzheimer, A.; Hetzel, M. Propionate CoAtransferase from Clostridium propionicum. Eur. J. Biochem. 2002, 269 (1), 372-80.

(58) Bhubalan, K.; Chuah, J. A.; Shozui, F.; Brigham, C. J.; Taguchi, S.; Sinskey, A. J.; Rha, C. K.; Sudesh, K. Characterization of the highly active polyhydroxyalkanoate synthase of Chromobacterium sp. strain USM2. Appl. Environ. Microbiol. 2011, 77 (9), 2926-33.

(59) Wong, Y. M.; Brigham, C. J.; Rha, C. K.; Sinskey, A. J.; Sudesh, $\mathrm{K}$. Biosynthesis and characterization of polyhydroxyalkanoate containing high 3-hydroxyhexanoate monomer fraction from crude palm kernel oil by recombinant Cupriavidus necator. Bioresour. Technol. 2012, 121, 320-7.

(60) Meng, D. C.; Shi, Z. Y.; Wu, L. P.; Zhou, Q.; Wu, Q.; Chen, J. C.; Chen, G. Q. Production and characterization of poly(3hydroxypropionate-co-4-hydroxybutyrate) with fully controllable structures by recombinant Escherichia coli containing an engineered pathway. Metab. Eng. 2012, 14 (4), 317-24.

(61) Leonardi, R; Zhang, Y. M.; Rock, C. O.; Jackowski, S. Coenzyme A: Back in action. Prog. Lipid Res. 2005, 44 (2-3), 12553.

(62) Vadali, R. V.; Bennett, G. N.; San, K. Y. Enhanced isoamyl acetate production upon manipulation of the acetyl-CoA node in Escherichia coli. Biotechnol. Prog. 2004, 20 (3), 692-7.

(63) Ohtake, T.; Pontrelli, S.; Laviña, W. A.; Liao, J. C.; Putri, S. P.; Fukusaki, E. Metabolomics-driven approach to solving a CoA imbalance for improved 1-butanol production in Escherichia coli. Metab. Eng. 2017, 41 (April), 135-43.

(64) Lee, S. Y.; Lee, Y. K.; Chang, H. N. Stimulatory effects of amino acids and oleic acid on poly(3-hydroxybutyric acid) synthesis by recombinant Escherichia coli. J. Ferment. Bioeng. 1995, 79 (2), 17780.

(65) Lindenkamp, N.; Peplinski, K.; Volodina, E.; Ehrenreich, A.; Steinbüchel, A. Impact of multiple $\beta$-ketothiolase deletion mutations in ralstonia eutropha $\mathrm{H} 16$ on the composition of 3-mercaptopropionic acid-containing copolymers. Appl. Environ. Microbiol. 2010, 76 (16), 5373-82.

(66) Budde, C. F.; Mahan, A. E.; Lu, J.; Rha, C.; Sinskey, A. J. Roles of multiple acetoacetyl coenzyme A reductases in polyhydroxybutyrate biosynthesis in Ralstonia eutropha H16. J. Bacteriol. 2010, 192 (20), 5319-28.

(67) Lindenkamp, N.; Volodina, E.; Steinbüchel, A. Genetically modified strains of Ralstonia eutropha $\mathrm{H} 16$ with $\beta$ - ketothiolase gene deletions for production of copolyesters with defined 3-hydroxyvaleric acid contents. Appl. Environ. Microbiol. 2012, 78 (15), 5375-83.

(68) Park, S. J.; Kang, K.-H.; Lee, H.; Park, A.-R.; Yang, J. E.; Oh, Y. H.; Song, B. K.; Jegal, J.; Lee, S. H.; Lee, S. Y. Propionyl-CoA dependent biosynthesis of 2-hydroxybutyrate containing polyhydroxyalkanoates in metabolically engineered Escherichia coli. J. Biotechnol. 2013, 165 (2), 93-8.

(69) Sato, S.; Maruyama, H.; Fujiki, T.; Matsumoto, K. Regulation of 3-hydroxyhexanoate composition in $\mathrm{PHBH}$ synthesized by recombinant Cupriavidus necator $\mathrm{H} 16$ from plant oil by using butyrate as a co-substrate. Journal of Bioscience and Bioengineering. 2015, 120 (3), 246-51.

(70) Brigham, C. J.; Budde, C. F.; Holder, J. W.; Zeng, Q.; Mahan, A. E.; Rha, C. K.; Sinskey, A. J. Elucidation of $\beta$-oxidation pathways in Ralstonia eutropha $\mathrm{H} 16$ by examination of global gene expression. J. Bacteriol. 2010, 192 (20), 5454-64.

(71) Peplinski, K.; Ehrenreich, A.; Döring, C.; Bömeke, M.; Steinbüchel, A. Investigations on the microbial catabolism of the organic sulfur compounds TDP and DTDP in Ralstonia eutropha H16 employing DNA microarrays. Appl. Microbiol. Biotechnol. 2010, 88 (5), 1145-1159.

(72) Choi, J.; Lee, S. Y. Factors affecting the economics of polyhydroxyalkanoate production by bacterial fermentation. Appl. Microbiol. Biotechnol. 1999, 51 (1), 13-21.

(73) Li, T.; Ye, J.; Shen, R.; Zong, Y.; Zhao, X.; Lou, C.; Chen, G. Q. Semirational Approach for Ultrahigh Poly(3-hydroxybutyrate) Accumulation in Escherichia coli by Combining One-Step Library
Construction and High-Throughput Screening. ACS Synth. Biol. 2016, 5 (11), 1308-1317.

(74) Kadoya, R.; Matsumoto, K.; Ooi, T.; Taguchi, S. MtgA deletion-triggered cell enlargement of Escherichia coli for enhanced intracellular polyester accumulation. PLoS One 2015, 10 (6), 1-11.

(75) Jiang, X. R.; Wang, H.; Shen, R.; Chen, G. Q. Engineering the bacterial shapes for enhanced inclusion bodies accumulation. Metab. Eng. 2015, 29, 227-37.

(76) Takase, K. Enhanced Synthesis of Poly(3-hydroxybutyrate) in Recombinant Escherichia coli by Means of Error-Prone PCR Mutagenesis, Saturation Mutagenesis, and In Vitro Recombination of the Type II Polyhydroxyalkanoate Synthase Gene. J. Biochem. 2003, 133 (1), 139-145.

(77) Song, C. W.; Lee, J.; Ko, Y. S.; Lee, S. Y. Metabolic engineering of Escherichia coli for the production of 3-aminopropionic acid. Metab. Eng. 2015, 30, 121-129.

(78) Martino, L.; Cruz, M. V.; Scoma, A.; Freitas, F.; Bertin, L.; Scandola, M.; Reis, M. A. M. Recovery of amorphous polyhydroxybutyrate granules from Cupriavidus necator cells grown on used cooking oil. Int. J. Biol. Macromol. 2014, 71, 117-23.

(79) Cruz, M. V.; Paiva, A.; Lisboa, P.; Freitas, F.; Alves, V. D.; Simões, P.; Barreiros, S.; Reis, M. A. M. Bioresour. Technol. 2014, 157, $360-3$.

(80) Garcia-Gonzalez, L.; De Wever, H. Valorisation of CO 2 -rich off-gases to biopolymers through biotechnological process. FEMS Microbiol. Lett. 2017, 364, 1-8.

(81) Lenz, O.; Schwartz, E.; Dernedde, J.; Eitinger, M.; Friedrich, B. The Alcaligenes eutrophus H16 hoxX gene participates in hydrogenase regulation. J. Bacteriol. 1994, 176 (14), 4385.

(82) Sambrook, J.; Fritsch, E. F.; Maniatis, T. Molecular Cloning: A Laboratory Manual; Cold Spring Harbor Laboratory Press: Cold Spring Harbor, NY, 1989. 